\title{
Blood-Brain Barrier Disruption as a Key Role Prob- lem in Multiple Sclerosis: A Novel Primary Prevention Strategy
}

\author{
Davide Frumento* \\ Department of Experimental Medicine, DIMES, University of Genoa, Genoa, Italy \\ *Corresponding author: Davide Frumento, Section of Biochemistry, Department of Experimental Medicine, Viale Benedetto XV 1 , \\ 16132 Genova (GE), Italy
}

\section{ARTICLE INFO}

Received: 幽 December 14, 2019

Published: 慧 January 06, 2020

Citation: Davide Frumento. Blood-Brain Barrier Disruption as a Key Role Problem in Multiple Sclerosis: A Novel Primary Prevention Strategy. Biomed J Sci \& Tech Res 24(2)-2020. BJSTR. MS.ID.004012.

Abbreviations: MS: Multiple Sclerosis; CNS: Central Nervous System; BBB: BloodBrain Barrier; CSF: Cerebrospinal Fluid; ER: Endoplasmic Reticulum; BBB: BloodBrain Barrier; AD: Alzheimer Disease; CD: Cognitive Dysfunction; ROS: Reactive Oxygen Species; MSCs: Mesenchymal Stem Cells

\section{ABSTRACT}

Blood-barrier disruption is known to be a typical feature of Multiple Sclerosis. Such a vasal permeability let lymphocytes infiltration, with consequent central nervous system inflammation and demyelination. It has been demonstrated that blood-brain barrier disruption also occurs with aging and among pathology like Alzheimer's Disease and Cognitive Dysfunction. With this in mind, it is clear that such phenomenon is a common trait between vey important and severe neurodegenerative diseases, letting happen neurological damages such as harmful cytokine diffusion within central nervous system and inlet of autoreactive immune cells. Interestingly, research about primary prevention of blood-brain barrier disruption is still lacking, so that the aim of this work is to propose a novel strategy to forestall this important etiological event. As it has been discussed throughout the paper, many risk factors have been identified, i.e. smoking habits, juvenile obesity, low vitamin D and oxidative stress. Since the above cited disorders onsets occurs at least after 20 years of age, a preventive strategy has been designed to be employed since the early childhood. Such plan includes eliminating smoking habits, the employment of a Mediterranean diet supplemented with vitamin $\mathrm{D}$ rich foods, introducing physical activity and the consumption of food containing antioxidants.

\section{Mini Review}

Multiple sclerosis (MS) is an idiopathic chronic inflammatory disease that affects the central nervous system (CNS) by demyelinating axonal processes; such pathology affects brain, spinal cord and optic nerves, sparing the peripheral nervous system. The sum of neurodegenerative and inflammatory processes generally results in discontinuous neurological disorders and progressive disability; such onset arises between 20 and 40 years of age. Since MS is known to be clinically heterogenous and displays different patterns, it could be safe to affirm the MS is a spectrum of diseases consisting by different pathological processes [1-5]. Such different forms are linked to virtually different pathophysiological pathways, though this a molecular demonstration is still lacking. Interestingly, within a single patient, the expressed pattern is homogenous even if the individual displays multiple lesions [6]. MS susceptibility can be conferred by different genes, such as those belonging to the major histocompatibility complex group, accountable for about $50 \%$ of genetic risk [7]. The current opinion recognizes MS as an immune-mediated process in which autoimmune T-cells enter the blood-brain barrier (BBB) acting by demyelinize axons, leading to various disabilities, and though research is untiringly going on, MS etiology is still largely unknown [8]. Histopathological evidences have been published, showing alterations of blood-brain barrier (BBB) in MS lesions matter [9-11]. Within this scenario it can be safely assumed that no definitive cure has been discovered, so it is reasonable to think that the best strategy is to identify risk factors, in order to try and prevent such disease. Since a primary prevention 
strategy toward BBB disruption is still lacking, the aim of this work is to identify the critical risk factors and propose a prevention plan.

\section{Blood-Brain Barrier Disruption}

The most commonly investigated aspect of blood-brain barrier (BBB) dysfunction is disruption [12], which is typically considered to consist in a seeming loss of non-penetrant molecules. In addition to its above cited role in Multiple Sclerosis (MS), recent studies state that BBB disruption occurs in normal aging, worsening in individuals suffering from mild cognitive impairment, which is considered to be an early sign of Alzheimer's disease $[13,14]$. A simple method to indirectly estimate the magnitude of $\mathrm{BBB}$ disruption in patients is the measurement of BBB impermeant proteins such as immunoglobulin $\mathrm{G}$ ( IgG) or albumin in cerebrospinal fluid (CSF). Anyhow, such measures can be mistaken by other central nervous system (CNS) deficits coming with aging, i.e. alterations in reabsorption and/or synthesis of cerebrospinal fluid (CSF) [15]. Furthermore, aging can coincide with a blood-CSFbarrier leakage, as well as with an altered protein synthesis [16,17]. In healthy mice ( 2 years old), it was observed a higher leakage of IgG within both cerebral cortex and hippocampus when compared with younger mice ( 3 months old); this finding suggests that BBB disruption occurred in this model. Such IgG increased leakage was linked with astrogliosis, endoplasmic reticulum (ER) stress, increased endothelial cell levels of TNF- $\alpha$, circulating concentration of IL- 6 and occludin expression in endothelial cells [18]. Molecular mechanisms of such phenomenon in aging have been found out and, surprisingly, comprehend under-expression of sirtuin-1 [19], a deacetylase related to senescence, lifespan and inflammatory responses [20].

Age-related BBB disruption could bring to a disease exacerbation through diffusion of potentially dangerous proteins into brain [14]. Anyway, it is not clear whether disruption will always lead to cerebral damage or not; for instance, some therapeutic strategies for bringing certain molecules to the brain have been carried out by temporarily disrupting BBB [21]. Latest study also reported that repeating transient disruption in human beings suffering from AD employing focused ultrasounds did not cause any severe adverse event [22]. Conversely, healthy rodents showed evidences of neurodegeneration when perfused with mannitol to disrupt BBB [23] and had an increasing in deposition of dangerous serum proteins in the CNS [24,25]. The seeming oxymoron, between attempting to use disruption as a therapeutic tool versus fearing it due to its bad effects on the CNS, underlines the complexities of BBB features as well as its role within brain pathophysiology.

\section{Primary prevention: A Novel Proposal}

According to literature, the main causes of blood-brain barrier (BBB) disruption are aging, inflammation and oxidative stress [26,27]. Although this phenomenon can be independent from pathogenetic processes associated to different diseases such as Multiple Sclerosis (MS), Alzheimer Disease (AD), Multiple
Sclerosis (MS) and Cognitive Dysfunction (CD), it still remains an important risk factor linked to the above cited diseases [9-11,2830]. Knowing that oxidative stress can lead to chronic inflammation by generating an imbalance between the synthesis of reactive oxygen species (ROS) and their elimination [31], and keeping in mind that aging causes neurodegeneration through oxidative stress [32], it is reasonable to infer that the most plausible molecular root of BBB disruption could be oxidative stress. Definitive cures and/or treatments to undo BBB disruption are still lacking and it is necessary to find a way to prevent this process, at least partially. Preliminary studies had been carried out in mice, employing mesenchymal stem cells (MSCs) in order to prevent BBB disruption after a transient ischemia [33] and administering topiramate to obtain the same result in a Type 2 Diabetes model [34].

With this in mind, it can be safely assumed that a primary prevention has still to be developed. Clearly, the only way is to eliminate all lifestyle-related risk factors, such as smoking and low vitamin D levels induced by both low dietary income and lack of sun exposure, as well as obesity during adolescence [35, 36]. Smoking habits can be stopped through various methods, including psychological therapy and nicotine-based drugs (e.g. nicotine patches, varenicline, bupropione) [37-39]; obviously, such methods depend on patient's will to actually quit smoking, and given that people freely choose start such habit, the only true primary prevention is to enhance public advertising against tobacco. Contrarily, low vitamin D levels can be both avoided by safely exposing individuals to sunlight, if possible since the early age [40], and by grating an appropriate dietary intake, supplementing meals with fish, mushrooms and sunflower oil [41]. Lastly, it is possible to hinder juvenile obesity by adopting healthy diets, such as Mediterranean one [42]. Adolescent overweight can be counteracted also by introducing an adequate physical activity, practiced on a regular basis $[43,44]$. The most innovative primary preventive strategy to lower both oxidative stress and inflammation is to consume antioxidant-rich food since childhood (e.g. tomato, carrots, cocoa, cranberries, grapefruit, pomegranate, etc.), since the early childhood $[45,46]$.

\section{Conclusion}

To conclude, it can be said that blood-brain barrier (BBB) disruption risk could be reduced, on a scientific basis, with the following primary prevention strategy in both children and teenagers:

a. By preventing or eliminating smoking habit;

b. By giving them a healthy diet like the Mediterranean one, complete of vitamin D rich foods;

c. By accustoming them to habitual physical activity;

d. By consuming antioxidants rich foods since the early childhood. 


\section{References}

1. Kakalacheva K, Leunemann JD (2011) Environmental triggers of multiple sclerosis. FEBS Lett 585(23): 3724-3729.

2. Chitnis T (2013) Role of puberty in multiple sclerosis risk and course. Clin Immunol 149(2): 192-200.

3. Franciotta D, Salvetti M, Lolli F, Serafini B, Aloisi F (2008) B cells and multiple sclerosis. Lancet Neurol 7(9): 852-858.

4. Fletcher JM, Lalor SJ, Sweeney CM, Tubridy N, Mills KH (2010) T cells in multiple sclerosis and experimental autoimmune encephalomyelitis. Clin Exp Immunol 162(1): 1-11.

5. Markovic Plese S, Pinilla C, Martin R (2004) The initiation of the autoimmune response in multiple sclerosis. Clin Neurol Neurosurg 106(3): 218-222.

6. Lassmann H, Brück W, Lucchinetti C, Rodriguez M (1997) Remyelination in multiple sclerosis. Mult Scler 3(2): 133-136.

7. Ramagopalan SV, Maugeri NJ, Handunnetthi L, Lincoln MR, Orton SM et al. (2009) Expression of the multiple sclerosis-associated MHC class II allele HLADRB1* 1501 is regulated by vitamin D. PLoS Genet 5(2): e1000369.

8. Ransohoff RM, Engelhardt B (2012) The anatomical and cellular basis of immune surveillance in the central nervous system. Nat Rev Immunol 12(9): 623-635.

9. Odoardi F, Sie C, Streyl K, Ulaganathan K, Schläger C, et al. (2012) T cells become licensed in the lung to enter the central nervous system. Nature 488(7413): 675-679.

10. Dodelet Devillers A, Cayrol R, van Horssen J, Haggani AS, de Vries HE, et al. (2009) Functions of lipid raft membrane microdomains at the bloodbrain barrier. J Mol Med 87(8): 765-774.

11. Misra M, Ganesh S, Shahiwala A, Shah SP (2003) Drug delivery to the central nervous system: a review. J Pharm Pharm Sci 6(2): 252-273.

12. Varatharaj A, Galea I (2017) The blood-brain barrier in systemic inflammation. Brain Behav Immun 60: 1-12.

13. Farrall AJ, Wardlaw JM (2009) Blood-brain barrier: Ageing and microvascular disease--systematic review and meta-analysis. Neurobiol Aging 30(3): 337-352.

14. Montagne A, Barnes SR, Sweeney MD, Halliday MR, Sagare AP, et al. (2015) Blood-brain barrier breakdown in the aging human hippocampus. Neuron 85(2): 296-302.

15. Chen RL (2011) Is it appropriate to use albumin CSF/plasma ratio to assess blood brain barrier permeability? Neurobiol Aging 32(7): 13381339.

16. Chen RL, Kassem NA, Redzic ZB, Chen CP, Segal MB, et al. (2009) Agerelated changes in choroid plexus and blood-cerebrospinal fluid barrier function in the sheep. Exp Gerontol 44(4): 289-296.

17. Chen RL, Athauda SB, Kassem NA, Zhang Y, Segal MB, et al. (2005) Decrease of transthyretin synthesis at the blood-cerebrospinal fluid barrier of old sheep. J Gerontol A Biol Sci Med Sci 60(7): 852-858.

18. Elahy M, Jackaman C, Mamo JC, Lam V, Dhaliwal SS, et al. (2015) Bloodbrain barrier dysfunction developed during normal aging is associated with inflammation and loss of tight junctions but not with leukocyte recruitment. Immun Ageing 12: 2.

19. Stamatovic SM, Martinez Revollar G, Hu A, Choi J, Keep RF, et al. (2019) Decline in Sirtuin-1 expression and activity plays a critical role in bloodbrain barrier permeability in aging. Neurobiol Dis 126: 105-116.

20. Rahman S, Islam R (2011) Mammalian Sirt1: Insights on its biological functions. Cell Commun Signal 9: 11.

21. Doolittle ND, Muldoon LL, Culp AY, Neuwelt EA (2014) Delivery of chemotherapeutics across the blood-brain barrier: Challenges and advances. Adv Pharmacol 71: 203-243.
22. Lipsman N, Meng Y, Bethune AJ, Huang Y, Lam B, et al. (2018) Bloodbrain barrier opening in Alzheimer's disease using MR-guided focused ultrasound. Nat Commun 9(1): 2336.

23. Salahuddin TS, Johansson BB, Kalimo H, Olsson Y (1988) Structural changes in the rat brain after carotid infusions of hyperosmolar solutions: A light microscopic and immunohistochemical study. Neuropathol Appl Neurobiol 14(6): 467-482.

24. Salahuddin TS, Kalimo H, Johansson BB, Olsson Y (1988) Observations on exudation of fibronectin, fibrinogen and albumin in the brain after carotid infusion of hyperosmolar solutions. An immunohistochemical study in the rat indicating longlasting changes in the brain microenvironment and multifocal nerve cell injuries. Acta Neuropathol 76(1): 1-10.

25. Merlini M, Rafalski VA, Rios Coronado PE, Gill TM, Ellisman M, et al (2019) Fibrinogen Induces Microglia-Mediated Spine Elimination and Cognitive Impairment in an Alzheimer's Disease Model. Neuron 101(6): 1099-1108.

26. Obermeier B, Daneman R, Ransohoff RM (2013) Development, maintenance and disruption of the blood-brain barrier. Nat Med 19(12): 1584-1596.

27. Erickson MA, Banks WA (2019) Age-associated changes in the immune system and blood-brain barrier functions. Int J Mol Sci 20(7): 1632.

28. Sweeney MD, Sagare AP, Zlokovic BV (2018) Blood-brain barrier breakdown in Alzheimer Disease and other neurodegenerative disorders. Nat Rev Neurol 14(3): 133-150.

29. Spencer JI, Bell JS, De Luca GC (2018) Vascular pathology in Multiple Sclerosis: reframing pathogenesis around the blood-brain barrier. J Neurol Neurosurg Psychiatry 89(1): 42-52.

30. Nation DA, Sweeney MD, Montagne A, Sagare AP, D’Orazio LM, et al (2019) Blood-brain barrier breakdown is an early biomarker of human cognitive dysfunction. Nat Med 25(2): 270-276.

31. Hussain T, Tan B, Yin Y, Blachier F, Tossou MC, et al. (2016) Oxidative stress and inflammation: what polyphenols can do for us? Oxid Med Cell Longev.

32. Niedzelka E, Smaga I, Gawlik M, Moniczewski A, Stankowicz P, et al (2016) Oxidative stress in neurodegenerative disease. Mol Neurobiol 53(6): 4094-4125.

33. Chung TN, Kim JH, Choi BY, Chung SP, Kwon SW, et al. (2015) Adiposederived mesenchymal stem cells reduce neuronal death after transient global cerebral ischemia through prevention of blood-brain barrier disruption and endothelial damage. Stem Cells Transl Med 4(2): 178185.

34. Salameh TS, Mortell WG, Logsdon AF, Butterfield DA, Banks WA (2019) Disruption of the hippocampal and hypothalamic blood-brain barrier in a diet-induced obese model of type II diabetes: prevention and treatment by the mitochondrial carbonic anhydrase inhibitor, topiramate. Fluids Barriers CNS 16(1): 1

35. Olsson T, Barcellos LF, Alfredsson L (2017) Interaction between genetic risk factors for multiple sclerosis. Nat Rev Neurol 13(1): 25-36.

36. Sayeed I, Turan N, Stein DG, Wali B (2019) Vitamin D deficiency increases blood-brain barrier dysfunction after ischemic stroke in male rats. Exp Neurol 312: 63-71.

37. Lancaster T, Stead LF (2017) Individual behavioural counselling for smoking cessation. Cochrane Database Syst Rev 3: CD001292.

38. Walker N, Parag V, Verbiest M, Laking G, Laugesen M, et al. (2019) Nicotine patches used in combination with e-cigarettes (with and without nicotine) for smoking cessation: a pragmatic, randomised trial. Lancet Respir Med.

39. Lindson N, Klemperer E, Hong B, Ordonez Mena JM, Aveyard P (2019) Smoking reduction interventions for smoking cessation. Cochrane Database Syst Rev 9: CD013183.

40. Holick MF (2017) Ultraviolet B radiation: the vitamin D connection. Adv Exp Med Biol 996: 137-154. 
41. Loznjak P, Jakobsen J (2018) Stability of vitamin $D_{3}$ and $D_{2}$ in oil, fish and mushrooms after household cooking. Food Chem 254: 144-149.

42. Buckland G, Bach A, Serra Majem L (2008) Obesity and the Mediterranean diet: a systematic review of observational and intervention studies. Obes Rev 9(6): 582-593.

43. Hills AP, Andersen LB, Byrne NM (2011) Physical activity and obesity in children. Br J Sports Med. 45(11): 866-870.

ISSN: 2574-1241

DOI: $10.26717 /$ BJSTR.2020.24.004012

Davide Frumento. Biomed J Sci \& Tech Res

(C) This work is licensed under Creative

Submission Link: https://biomedres.us/submit-manuscript.php
44. Kotz CM, Perez Leighton CE, Teske JA, Billington CJ (2017) Spontaneous physical activity defends against obesity. Curr Obes Rep 6(4): 362-370.

45. Serafini M, Peluso I (2016) Functional foods for health: the interrelated antioxidant and anti-inflammatory role of fruits, vegetables, herbs, spices and cocoa in humans. Curr Pharm Des 22(44): 6701-6715.

46. Franco R, Martinez Pinilla E (2017) Chemical rules of the assessment of antioxidant potential in food and food additives aimed at reducing oxidative stress and neurodegeneration. Food Chem 235: 318-323.

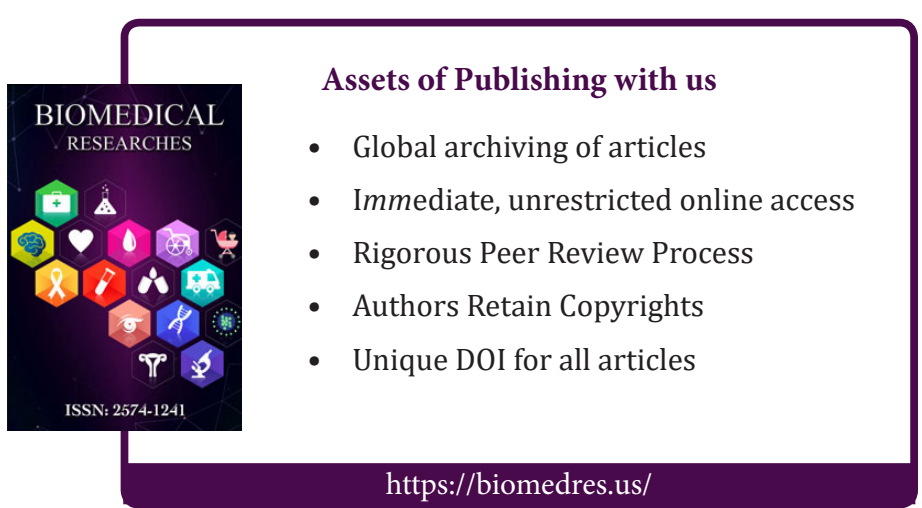

